\title{
A deliberative approach to valuation and precautionary management of cold water corals in Norway
}

Jannike Falk-Andersson ${ }^{1 *}$, Naomi S Foley ${ }^{2}$, Claire W Armstrong ${ }^{1}$, Sybille van den Hove ${ }^{3}$, Thomas M van Rensburg ${ }^{4}$ and Rob Tinch ${ }^{5}$

\author{
* Correspondence: \\ Jannike.Falk-Andersson@uit.no \\ ${ }^{1}$ Marine Resource Economics group, \\ Norwegian College of Fishery \\ Science, UiT The Arctic University of \\ Norway, 9037 Tromsø, Norway \\ Full list of author information is \\ available at the end of the article
}

\begin{abstract}
This paper explores management challenges in relation to human impacts on cold water corals (CWC) in Norway. CWC are a slow growing organism about which there is uncertainty regarding distribution and values. We discuss area closures to protect this environmental public good against destructive fishing practices. Focus groups were combined with questionnaires to inform precautionary management measures that can be used to protect known CWC as well as areas where CWC are thought to exist. The research finds that respondents believe CWC are valuable and should be protected, but that this requires information on their presence and importance. Furthermore, priorities for protecting CWC differed between group discussions and the questionnaire responses. Use-values, particularly habitat supporting fish production, dominated the focus group discussions, while non-use and intrinsic values were emphasised in the questionnaire responses. Respondents rejected the use of the precautionary measure of temporary closures to gain information on CWC presence. Reasons were costs to fishers, and the rejection of the premise that precautionary closures would prevent further damage. This study shows that both use- and non-use values are effective arguments motivating people to support policies for nature protection. However, they are not sufficient to motivate support for precautionary measures that would provide significant but uncertain benefits for known costs. To motivate support for precautionary policies, there is a need to communicate better the types of organisms, services and values that may be lost without protection.

Keywords: Valuation; Deliberative; Cold water corals; Ecosystem services; Precautionary principle
\end{abstract}

\section{Introduction}

The many dismal experiences from fisheries management (Myers and Worm 2003, Jackson et al. 2001) have led to the realization that in order to secure sustainable utilization of marine resources, a broader ecosystem management approach is needed. This involves widening the focus from single stocks to ecosystems, including human activities and values (Garcia et al. 2003, Aanesen et al. 2012). Stakeholders and citizens use ecosystem resources and benefit from their services in different ways. Interests may conflict with respect to what is seen as appropriate use of the resources. Furthermore, resource conflicts may arise in cases where the resource is a common public 
good, externalities may occur, and legal rights and obligations are poorly defined (Armstrong and van den Hove 2008, Glenn et al. 2010). The management changes required will therefore be most effectively achieved if a wide range of stakeholders become involved in issues pertaining to the sustainable use of marine resources.

This paper addresses the particular case of cold water corals (CWCs), which are often badly damaged by certain fishing practices, particularly bottom trawling. There is a conflict between current, known fishing values and future, uncertain values associated with conservation, biodiversity protection and other uncertain or unknown opportunities, including fishing. There is also significant uncertainty regarding the roles and functions of CWCs in marine ecosystems and the on-going and future costs of damage. This creates challenges for policy formation because improving the knowledge base requires resources, takes time, and may be unfeasible with the tools currently available to marine scientists. While decisions therefore have to be made without full scientific understanding, policy can nevertheless be informed by better knowledge of stakeholder and citizen perceptions, beliefs, and attitudes towards the issues at stake. The potential role of stakeholder input in decision making processes will be discussed here.

The almost total lack of public familiarity with CWC and its relation to ecosystem functions and services makes this resource difficult to value using standard stated preference valuation techniques, such as contingent valuation or discrete choice experiments. Recent attempts have been made (LaRiviere et al. 2014), but the interpretation of values elicited under such conditions of unfamiliarity, uncertainty and ill-defined preferences is problematic (see Wattage et al. (2011) for more detailed discussion). In order to support decisions, reducing peoples' values to an uncertain monetary entity may not be sufficient. To delve more deeply into the ways in which people understand and reason about policy decisions that have an impact on CWC, we therefore employed a deliberative approach (Wilson and Howarth 2002, Lo and Spash 2013). Although well-developed and integrated in decision support (Söderholm 2001, Morgan 1996), studies that apply deliberative techniques to the precautionary principle by involving citizens and stakeholders are still rare (see Mason et al. (2010) for one example). We combined group discussions and individual questionnaire responses in three focus groups carried out in Norway, to explore attitudes towards CWC and related services and values. Questions focused on individual and group thinking regarding the tradeoffs between conflicting values; in particular, opinions regarding trade-offs between future potential uses versus current fishery values were studied.

Since this study looked into Norwegian CWC, we consider the Norwegian populace at large as the relevant population. Both stakeholder groups and individual citizens are of interest (Kahane et al. 2013). Fishers have a particular stake since regulations may affect their activity directly, and since they believe CWC are important to fish (Armstrong and van den Hove 2008). However, both fishers and non-fishers may have an interest as citizens in maintaining fish populations and securing other CWC values, including non-use values. CWC - the "rainforests of the sea" - may also be of more global interest, but for practical reasons we limited attention to the Norwegian population.

To tease out nuances regarding attitudes to CWC in the context of the scientific uncertainty about their extent, condition and functions, perceptions regarding protection of CWC were studied in two different contexts: 
1) Permanent protection of known CWC grounds because they provide benefits or represent values now and in the future (albeit with uncertainty about these benefits), and

2) Temporary protection of candidate areas for the purpose of obtaining information on the presence or absence of cold water corals.

Both issues were discussed in the focus groups as well as in questionnaires answered by each participant during the meetings, in order to gauge differences between individual perceptions and group deliberations.

The objective of the study was to investigate the use of deliberative approaches to provide information relevant to decision making and management, especially in the context of the implementation of the precautionary principle. Insights gained are useful in assessing how CWC values can best be captured and communicated.

\section{Background}

\section{Cold water coral and the precautionary principle}

Bottom trawling has been the main threat to cold water corals. Together with other drivers such as oil/gas extraction, climate change and ocean acidification, corals and other benthic habitats are experiencing increasing anthropogenic pressures (Foley et al. 2010). CWC is a slow-growing, reef-building organism found in all the world's oceans (MacIsaac et al. 2001). Though known to both fishermen and scientists for centuries, the degree of understanding of these organisms and their ecosystem functions is limited (Foley et al. 2010). The damage caused to CWC by fishing pressure is reflected in the substantial estimated declines in CWC coverage, including in Norwegian waters, where damage has been estimated at 30-50 \% (Fosså et al. 2002). Additionally, their slow growth implies that they do not completely recover from damage, which, at least in the context of reefs, is largely irreversible on human-relevant timescales (Foley et al. 2010). The marine protected areas established in order to protect cold water corals cover $2445 \mathrm{~km}^{2}$ or $0.3 \%$ of the Norwegian Exclusive Economic Zone. Furthermore, Norwegian legislation demands that special care should be taken when fishing, in order to avoid damage to corals (Anonymous 2004).

Uncertainty regarding ecosystem functions and values in combination with irreversibility of damage is generally viewed as a trigger for implementation of the precautionary principle in management (UNESCO 2005, The European Environmental Agency, The 2001), though precautionary action is not always taken in practice. There are many different definitions of the precautionary principle, resulting in misunderstandings that have been identified as one of the barriers to its use (The European Environmental Agency, The 2001). Key elements of the principle relevant to this study can, however, be broadly agreed to include: the need for decision makers to anticipate potential harm before it occurs or becomes likely; the justification to act to prevent or minimize the harm; and accounting for the advantages and disadvantages of action and inaction (Tinch et al. 2011). The latter implies an exploration of values - these may be considered in terms of monetary costs and benefits, but this is not a necessary requirement.

\section{Cold water coral and valuation}

Although the uncertainty and irreversibility associated with CWC damage should be sufficient to invoke the precautionary principle, the realities of policy formation in most 
of the world means that the cost of action is an important criterion. Information about the costs and benefits (or more generally advantages and disadvantages) of action and inaction, about the consequent trade-offs, and about the ways in which people consider and value the issues at stake, form important inputs into the policy process (Morris et al. 2000). Identification and sometimes valuation of ecosystem services can be used to make such trade-offs explicit. For many of these services their value is not reflected in any market, either directly or indirectly, making market-based and revealed preference methods inapplicable. A number of stated preference methods have been developed to elicit individuals' valuation of these services (see for example Liu et al. (2010), Defra (2007)). LaRiviere et al. (2014) apply a discrete choice model to study how the effect of signals regarding respondents' knowledge affects willingness to pay in the case of protection of cold water coral in Norway. The results showed that the Norwegian public were in fact willing to pay for cold water coral protection in Norway, and that the respondents' beliefs about their own knowledge affected this willingness to pay. The study does however not give insight into the more complex perceptions regarding management and option values. Glenn et al. (2010) used a discrete choice model to estimate the Irish population's willingness to pay for protection of CWCs. Although the study did not find a statistically significant willingness to pay, it did reveal a strong preference for a ban on bottom trawling where CWC are thought to exist. Furthermore, a large percentage of those surveyed claimed to value conservation of corals. Respondents stated that they would like to see CWC protected for future generations, for their role as a perceived essential fish habitat, for their existence value and also for the option to use or see them in the future (Glenn et al. 2010).

One possible explanation for this latter seemingly contradictory result is the public's lack of familiarity with CWC, limited visibility and very limited potential for first-hand exposure. Other explanations are rejection of various features of the study, including the payment mechanism. In effect, the restrictive nature of the stated preference valuation instrument may prevent it from capturing in monetary terms the values and attitudes that are held by the respondents and that they express in response to non-monetary elicitation techniques. A discursive approach, on the other hand provides a setting in which individuals become exposed to the ideas of others, which facilitates discussions and thoughtful consideration of public (not just private) values (Morgan 1996). It is in this light that we apply a deliberative approach to valuation of CWC; deliberation allows more time for learning and thereby for preference or attitude formation relating to an unfamiliar issue.

\section{Ecosystem services and values}

The first synthesis report of The Economics of Ecosystems and Biodiversity (TEEB 2010) introduced the idea of a tiered approach to values in environmental assessment and management. This considers the integration of value evidence in decision making as existing on different levels, from basic and general societal recognition of values integrated in social norms, through formal demonstrations and assessments of values, to full use of value evidence as key components of management tools. These tiers of recognising, demonstrating and capturing value require various levels of identification and methods for measurement of values arising from ecosystems. The current dominant framework is based on the identification of the ecosystem services provided to humans. Describing 
ecosystems and their functions in terms of the services people benefit from is intended to help articulate the importance of ecosystems and raise awareness of the many ways in which they support and provide value for human life and well-being. This translation is intended to offer a framework for representing public values for conservation in a more utilitarian form, rather than a more holistic environmental view (Barkmann et al. 2008). Many frameworks for assessing ecosystem services have been developed, for example by TEEB (2010), in national ecosystem assessments (see http://catalog.ipbes.net/) and in particular the Common International Classification of Ecosystem Services (CICES 2013), though there is as yet no agreement on a single approach. The Millennium Ecosystem Assessment (MEA 2005) framework divides ecosystem services into four categories (that remain, broadly speaking, the basis for more recent frameworks): provisioning, regulating, cultural and supporting services. Figure 1 illustrates the MEA framework adapted for

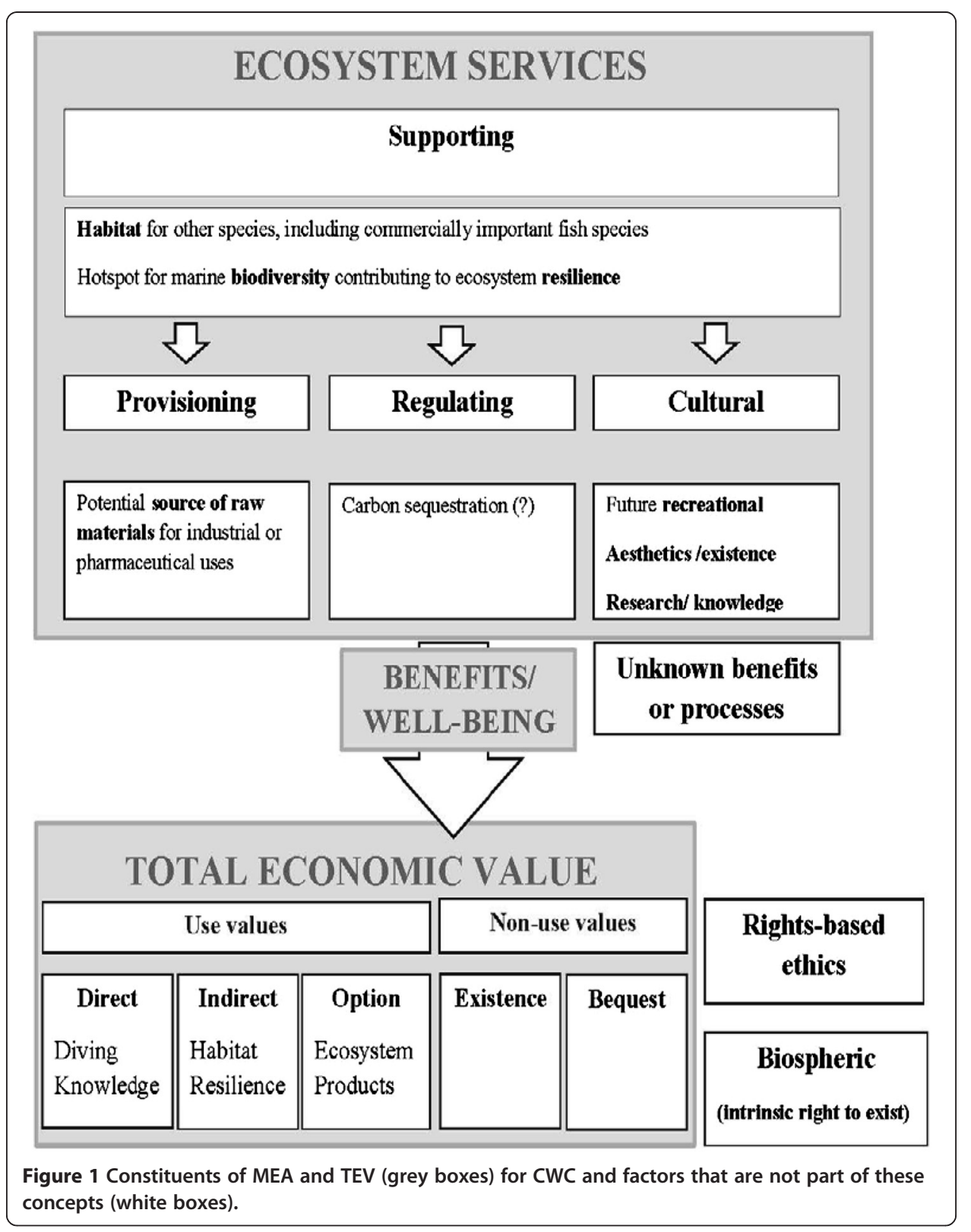


CWC, starting with the more indirect supporting services that can potentially feed into the direct provisioning, regulating and cultural services.

Provisioning services are products used by humans that are obtained directly from ecosystems. As of today CWC provide no direct provisioning services, apart from a few cases of mining and collection of corals to make jewellery. However, CWC are potentially a source of original raw materials for industrial and pharmaceutical uses (Foley et al. 2010). The unusual characteristics of deep-sea organisms, their unique adaptations that enable them to survive in dark, extreme temperatures and highly pressurized environments, offer unique opportunities, making them the subject of considerable excitement in the scientific community, with many potentially interesting commercial possibilities (Armstrong et al. 2010, Arico and Salpin 2005).

Regulating services are benefits obtained from the regulation of ecosystem processes such as climate and water regulation, erosion control and water purification. CWC could offer regulating services such as the sequestration of carbon, providing a climate change mitigation benefit (Foley et al. 2010).

Cultural services are non-material benefits obtained through, for example, recreation, aesthetic enjoyment, inspiration and learning. To date there is no direct recreational use value for CWC, apart from the unique case of Trondheim fjord, Norway, where they are found at depths accessible for recreational diving. Future recreational use may be possible, for example employing submersibles. Indirect aesthetic use is possible via films and books (Foley et al. 2010). Part of the willingness to protect CWC reflects the charismatic nature of these resources (Armstrong and van den Hove 2008) and that people want to preserve them simply for their existence or for future generations (Glenn et al. 2010). CWC provide educational and scientific services for many people involved in learning about the marine environment. CWC could also provide archives recording intermediate to sub-surface water temperatures and salinity and serve as a good climate change proxy (Lutringer et al. 2005, Puglise et al. 2005).

Supporting services are those necessary for the production of all other ecosystem services such as nutrient cycling, primary production and habitat. Supporting services related to CWC specifically include habitat, biodiversity and resilience (Figure 1). These deep-sea structures have been shown to harbour high biodiversity (Freiwald et al. 2004) and to support important habitat functions, notably with regards to fish nurseries, refugia to hide from predators and feeding areas (Freiwald et al. 2004). Both are likely to contribute to greater resilience of ecosystems and thereby the capacity to cope with disturbance (Foley et al. 2010). CWC seem to attract fish concentrations (Husebø et al. 2002), in turn also attracting fishermen (Armstrong and van den Hove 2008).

The total economic value (TEV) framework (Pearce and Moran 1994) has been used to value the benefits or well-being generated by provisioning, regulating and cultural services (Figure 1), with supporting services being valued through their contribution to the other services (Defra 2007). TEV divides economic values into use values, non-use values and option values (Pearce and Moran 1994). Use values arise from direct or indirect use of a resource, while non-use values are derived from the value of knowing that something exists and/or that other people, including future generations, may benefit from a resource. Option values are a third category capturing uncertainty regarding future use or provision of the resource: what is it worth giving up today in order to 
keep those future uncertain options available? A related concept is quasi option value which refers to the value of future information which can be protected by delaying an irreversible development (Perman et al. 2011). In this case, it would relate to willingness to pay to avoid irreversible consequences of development today, given the expectation of future increase in knowledge related to the resource (Perman et al. 2011). An important goal of this study was to find out if focus group participants support the use of temporary CWC protection measures for the purpose of obtaining information on the presence of cold water corals in the future.

Given that research on CWC is relatively recent and the degree of knowledge is limited, many of their services are unknown or potential services, i.e. option values. One example is bioprospecting: there is a value now to delaying or avoiding decisions that could reduce deep-sea genetic diversity, due to the unknown future potential for these genetic resources to contribute to human wellbeing (Armstrong et al. 2012).

Furthermore, since damage is essentially irreversible within a time frame relevant to humans, due to the low growth rate of CWC, the concept of quasi option value is important. While the benefits of preservation are uncertain today, they could become more certain through time as information increases (Foley et al. 2010). Valuation of option and quasi-option values is closely linked to the precautionary principle, as the valuation applies to processes of complex social-ecological systems, characterised by non-linearity and thresholds and also by uncertainty, ignorance and ambiguity for which it is not possible fully to quantify scientific uncertainty (UNESCO 2005).

The TEV framework, as usually applied, is grounded in values derived from individual preferences, and is therefore focused on utilitarian values associated with an ecosystem. This does not mean that only personal use is covered - the non-use category covers altruistic values - but the key reference point remains the preferences of individuals, expressed in monetary terms which is then aggregated. Abson and Termansen (2011), however, stress that it is only appropriate to apply the TEV framework when it captures the values that humans associate with the ecosystem services of concern. TEV has been argued to be incompatible with rights-based ethics as a basis for decision making, because concerns for doing the right thing, meeting social norms, and recognition of an intrinsic right to exist independent of human benefit, have been found to be important features of human attitudes towards environmental issues (Spash 2006). On the other hand, these concerns influence human preferences and their expression, and non-use values - part of TEV - may be concerned with unselfish motives. Although rights based ethics may seem to require absolute positions (the rejection of any trade-off), in fact, because of the existence of an irreducible plurality of values, absolute 'rights' of different people often conflict and in such cases trade-off or compromise is literally inevitable (van den Hove 2006). Discursive, deliberative based approaches are one way of dealing with a plurality of values and world views that depart from individual-based TEV. Appropriate choices depend on contexts, and 'problems' when applying stated preference methods may be interpreted as a sign that people feel uncomfortable with the use of individual preference based methods in a given situation. This is often associated with rejection of the implied property right or other forms of protest bidding. Figure 1 illustrates the constituents of MEA and TEV in terms of CWC, as well as the factors that are not included in these concepts. In this paper, we have chosen to discuss the results in terms of the TEV concept and the intrinsic right for something 
to exist, since we were especially interested in exploring the support for protecting option values.

\section{Deliberative approaches}

Many environmental issues are characterised by complexity, uncertainty, large temporal and spatial scales, and irreversibility (van den Hove 2000). These features may favour deliberative methods, as these methods allow for greater clarification and interaction. Deliberative methods that focus more on negotiation and consensus building may also be viewed as better suited to valuing public goods, including many environmental services (Howarth and Wilson 2006, Sagoff 1998, Kumar and Kumar 2008). In the academic discussion on environmental planning there has also been a tendency towards communicative rationality where agreement is reached based on shared validity criteria (Gezelius and Refsgaard 2007) and plurality of values makes it more appropriate to speak of compromise rather than consensus solutions (van den Hove 2006).

There are a number of different deliberative approaches to valuation, from loosely defined 'group-based approaches' to more codified methods of deliberative polling, citizens' juries, focus groups and deliberative monetary valuation (DMV). Table 1 illustrates some of the diversity of deliberative methods applied in valuation. Discursive approaches can be used to derive monetary values, as in DMV, though this has been criticised for example by Niemeyer and Spash (2001) who compare DMV with costbenefit analysis, and find the same theoretical limitations in both, arguing especially against the "allure and simplicity of a single number as the basis for determining policy" (op. cit. p.583). Non-monetary methods can also be used to allow expression of preferences in units other than money, and may focus on direct expression of preferences for outcomes (Tinch et al. 2011).

We used a focus group approach to deliberation: our objective was not to determine a single numerical 'value', but rather to explore wider attitudes and preferences with regards to CWC and their management. Furthermore, with such a complex and unfamiliar set of issues, use of groups in which individuals shared key characteristics, such as the same

Table 1 Summary of deliberative methods to valuation (Perman et al. 2011, Turner et al. 2010, Niemeyer and Spash 2001).

\begin{tabular}{ll}
\hline Method & Description \\
\hline Deliberative Polling & $\begin{array}{l}\text { A random opinion poll prior to an invitation to one or several meetings. } \\
\text { Respondents are given the opportunity to listen to and question expert } \\
\text { witnesses, as well as discuss the issue within the group before being given } \\
\text { the original questionnaire once again. }\end{array}$ \\
& $\begin{array}{l}\text { A costly approach, where the number of attendees must be substantial if } \\
\text { the results are to meet the standards of regular opinion polls. }\end{array}$ \\
& $\begin{array}{l}\text { Consists of a smaller number of representatives. Less resource demanding } \\
\text { than polling, and deemed to be equally legitimate. }\end{array}$ \\
Focus Groups & $\begin{array}{l}\text { Selection of the public representing a specific type, and seeking a 'focus' } \\
\text { view for that type. Replicates of a number of different types then represent } \\
\text { a range of typical views. } \\
\text { Applies more stringent stated preference methods to a discursive approach. } \\
\text { Small groups that in total represent society are given concrete valuation } \\
\text { problems for discursive evaluation. }\end{array}$ \\
\hline
\end{tabular}


interest or employment, eased the discussion, and allowed some consensus or compromise reaching, and clear identification of points of disagreement.

\section{Method}

Focus groups were held in Norway in October 2011. Three groups were chosen to examine similarities and differences in opinion of people with varying interests, backgrounds and connections to the ocean: a commercial user group (6 fishers), a recreational user group (7 sailors), and a group with no specific connection to the ocean (7 singers from an inland choir). The fishers lived in a small coastal community, the sailors were coastal city dwellers, while the choir came from a small inland community. The three groups may be seen as a continuum from stakeholder to citizen (Soma and Vatn 2010). All participants within each group were adults and already knew each other through the activities they had in common. This helped to ensure free and open discussions. The groups were reached via contact with their respective organisations. The choir and the sailors club were offered a token contribution to the club. Members in these two clubs participated voluntarily and received no personal payment. Each focus group involved a facilitator guiding the discussion and an assistant taking notes on the discussion as basis for subsequent analysis. The small group sizes allowed sufficient documentation of the discussions. The focus groups took place in meeting rooms at hotels and participants were offered refreshments.

A protocol was prepared as an aide to prompt and engage participants in discussion (Online Additional files 1 and 2). The protocol was open to provide flexibility but a number of objectives with related questions were set to steer the discussion. The general format was as follows: the researchers explained the background for the study and that the aim of the focus groups was to explore with the participants their perceptions and opinions regarding the topic. Then the participants were asked to introduce themselves. Throughout the focus group a discussion of a topic was followed by the participants filling in the corresponding section in a questionnaire (Online Additional files 1 and 2). Thus, prior to filling in the questionnaire, the participants shared their perceptions and opinions.

The first part of the focus group was kept broad, to ease participants into the discussion and to get information on their uses of the sea, opinions of the state of the sea in general, and knowledge of the products and functions the sea provides. After this, since $\mathrm{CWC}$ is largely an unknown good, some general information on CWC was given along with a digital presentation, on their biology, what is known about CWC (they provide habitat for fish and $\mathrm{CO}_{2}$ storage, and their high biodiversity is a potential source of genetic resources for bio-prospecting), the threats to them (trawling, oil and gas industry, mining, ocean acidification), and alternatives for their management (closures, gear restrictions and eco-labelling). Then respondents were asked whether they had heard of CWC prior to participation in the focus group, whether they thought people in general would have heard about CWC, their knowledge of deep-water fisheries, as well as attitudes to management of CWC (should they be protected and why/why not, how should they be protected). One of the goals of this study was to obtain information about how respondents think about full protection of known coral grounds versus temporary protection of sites thought to have CWC. In order to make sure that 
respondents fully understood this, they were presented with two different options for closures: 1) closure of areas only after corals have been documented in an area, and 2) closure of a wider range of areas while waiting for areas to be mapped for corals. It was made very clear that the former would imply that corals could be damaged forever (irreversible action) while waiting for mapping, while the latter would be a precautionary action to ensure damage could not occur while obtaining information on the presence of cold water corals, but would have greater short-term implications for the fishing industry.

Key words from the discussion were noted on a black board and the administrator took notes as the basis for qualitative analysis. These notes were later compared to the answers in the questionnaires. The use of scientific terminology was avoided and the presentation was given in Norwegian. Care was made to not use value laden terms such as "services" and "values" in order to avoid causing a bias in the discussion, particularly with respect to reasons for protection. During the discussions the moderator specifically encouraged less active participants to contribute, and underlined that there was no right or wrong answer. If needed, the moderator probed into issues that had not surfaced during the discussions. In all the focus groups the participants were vocal, showed interest and contributed enthusiastically to the debate.

After discussions, the corresponding sections in the questionnaire were filled in. The questionnaire listed values corresponding to TEV that CWC represents, as well as their intrinsic right to exist, but without using scientific jargon. Including an individual questionnaire along with focus groups is a practice that is not uncommon (Morgan 1996). It allows a check for bias that can arise due to differences among participants in terms of how dominant they are in the discussions. Further rationales for combining individual and group interviews point to the greater depth of the former and improved breadth of the latter (Crabtree et al. 1993), and to the ability to explore specific opinions further (Duncan and Morgan 1994). A number of questions were posed in the questionnaire with alternative answers which were elicited through a discrete visual analogue scale, in addition to options of not knowing or not caring. The questionnaire asked whether the respondents agreed that CWC should be conserved because of their potential for bio-prospecting (direct use-value), as habitat for fish (indirect use-value), carbon storage (indirect use-value), future generations' use of CWC (bequest value), because they have the right to exist independent of humans (intrinsic right to exist), and/or because of the large uncertainties regarding the values CWC represent (option value). The respondents were also asked whether they would prefer closing areas for one year, 2-5 years, five years or until mapping of CWC is completed. These questions gave us preferences regarding which of the values related to CWC the respondents emphasised, as well as attitudes to precautionary action. The respondents rated the questionnaire statements from disagree (1-2), neutral (3) to agree (4-5) or "don't know/ don't care". The data were pooled and the percentage of respondents that "agreed" was calculated for each statement. The survey responses are displayed in simple graphs, since the low number of participants does not justify further statistical analysis. In this study we only compare the group and survey responses with respect to reasons why cold water corals should be protected and how this should be carried out, as these are the most relevant issues related to management. 


\section{Results}

The following presents attitudes relating to CWC based on deliberation and questionnaire findings. The results from the surveys are compiled from the three focus groups, totalling 18 responses, as two surveys were incomplete.

The first issue was to address the protection of known coral areas. The reader is reminded that the objective was to elicit the values focus group participants associated with CWC and other factors considered important in determining whether they should be protected. The emphasis here is on the protection of cold water corals because they may provide services and represent values now or in the future, for coral areas that are known, even if there is still uncertainty about the specific level of benefits. During the discussions, fishers recognised the indirect use-value that CWC habitat provides for fish stocks, including commercial species such as redfish and halibut. For this reason, they would be glad of coral protection, but were concerned about the size of buffer zones around the coral areas which would prohibit them fishing close to the corals. Furthermore, the fishers stated that they had become so efficient that the fish needed some protection, and that they already tried to avoid CWC areas, in part due to loss or damage to fishing gear when fishing on coral. Both the fishers and some of the choir were opposed to the protection of CWC merely for their beauty (existence value). However, some members of the choir felt this might change if it was possible to see the corals. The remaining members of the choir felt, for them, it was enough to know of the existence of CWC (non-use value/ existence value) to warrant protection, but they thought that the general public would need to be able to see the corals to justify protection. The sailors had a similar attitude. The discussions also revealed that the fishers were opposed to closures based on suspicions of their existence (option value) and emphasized that they must have a function in the food chain in order to be protected (indirect use-value).

There were important differences between the questionnaires and the group discussions. While use-values were emphasised in the discussions, participants favoured non-use and intrinsic values of CWC in the questionnaires. The questionnaires showed that $89 \%$ would like to protect CWC for future generations (bequest values) and $83 \%$ for their intrinsic right to exist. Similarly, a high percentage, $82 \%$, wanted to protect corals for their option values. Figure 2 shows the aggregated results from the

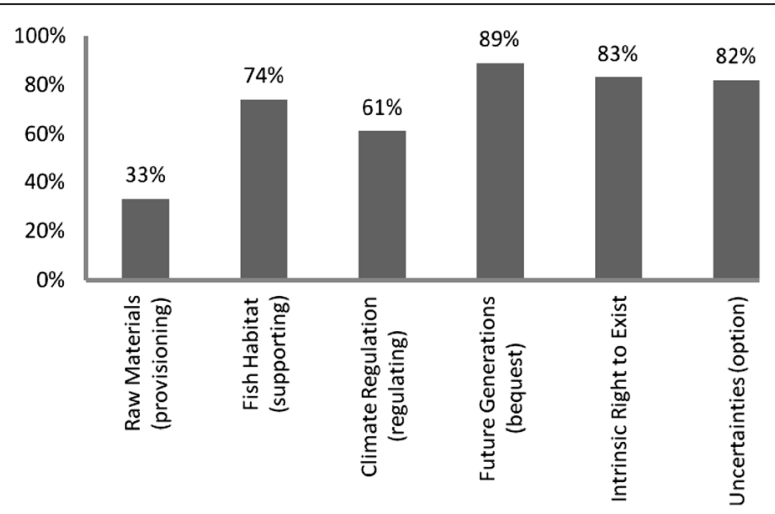

Figure 2 Reasons that CWC should be protected, questionnaire results. 
questionnaires for the three focus groups on the reason why CWC should be protected.

The second major goal was to evaluate attitudes towards temporary closures specifically for the purposes of obtaining information about the presence of CWC, thereby protecting quasi option values. The fisher and sailor focus groups showed a general opposition to the idea of closures in order to map coral areas and to closures based on the potential for coral presence. All of the groups expressed concern about the economic consequences to industry, particularly fisheries, from temporary closures. While some suggested that coral areas should be managed based on the best available knowledge of their services today, the importance of a proper justification for closures based on knowledge of the ecosystem services CWC provides was stressed. Some suggested that a one year closure could be acceptable if compensation was provided for loss of income. Others felt more surveying was required before closures - again, in effect, rejecting the research premise that the closures would be a necessary precautionary action in order to allow a programme of surveying. While being aware of the economic consequences of closures to fishers, the inland choir did not show as much opposition to the idea of closing all areas until the mapping was done. The fishers and the sailors found it unreasonable to close an area to fishing for a year to ascertain whether corals were present when fishing had occurred for 30 years, on the grounds that the damage would already have been done in these areas.

The question posed in the questionnaire was 'while mapping is taking place would you be willing to close areas for (a) 1 year; (b) 2-5 years; (c) 5 years; (d) until mapping is complete. The results from the questionnaires supported the outcomes from the discussions. The majority of the agree statements were for a closure of one year, and only $47 \%$ of those surveyed agreed to this. As the time increased the willingness to support closures to increase knowledge decreased as shown in Figure 3. Approximately $75 \%$ of those surveyed were opposed to the idea of closing areas for 2-5 years, with only $6 \%$ support for a 5 year closure of potential coral areas. The majority, $61 \%$, also disagreed with a closure until mapping was complete. The inland choir made up all of the $17 \%$ of those willing to close areas until the mapping was complete.

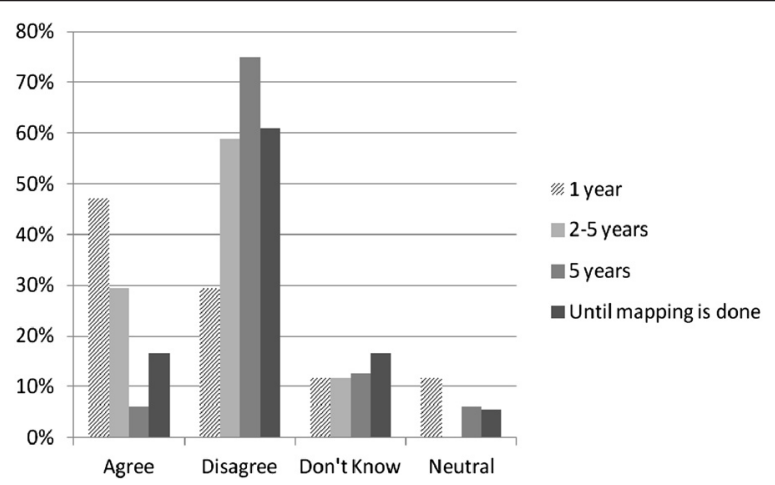

Figure 3 Responses to time closures while searching for CWC. Indication of quasi option values. 


\section{Discussion}

\section{Equality in exclusion}

Although fishers were in favour of measures to protect known CWC areas, they stressed that if they were to be excluded, the same would have to apply to all types of fishing, including recreational fishing, as well as the oil industry. The attitude that protection of CWC should also apply to all types of fishing and industries was also reflected in responses by Norwegian fisheries organisations to the draft regulation of CWC in Norwegian waters (Armstrong and van den Hove 2008).

\section{Irreversibility, precaution and perceptions of harm}

While participants generally recognised the potential services and values associated with CWC, most were not willing to close areas with a view to obtaining more information on their presence and functions due to the consequences for fisheries. Thus, when faced with trade-offs, protecting the known existing use values of the fisheries seemed to weigh more substantively than protection of uncertain potential values. This suggests that they did not necessarily support a precautionary approach to managing CWC. The discussions, however, also reflected that the issue of irreversibility may not be straightforward. For example, some mentioned that local loss of corals could be acceptable if their existence was secured globally. Finally, while the fishers stated in discussions that they had become so efficient that protection was needed and emphasised the supporting services of known coral areas, they rejected the hypothesis that there could be any option values associated with CWCs in fished areas, on the grounds that the damage had already been done. Thus, we cannot conclude that our respondents necessarily reject a precautionary approach outright, since the additional damages of continuing trawling while mapping are perceived by some to be limited. Essentially, this is rejecting a premise in the research method, and serves to illustrate that this problem of premise-rejection is not limited to stated preference instruments - though with the difference that it is more easily detected in a discursive setting. Rejection of the research premise may in particular be likely when user groups have extensive experience with certain aspects of a resource. Resolving such differences of opinion would require adjusting the premises in the research questionnaire, which could be achieved through repeated focus groups, or through methods other than focus groups, for example by applying weights in a multi-criteria mapping (http://www.multicriteriamapping.org/) or social multi-criteria evaluation (Munda 2004). However adjusting the premises in the survey for each focus group was not possible in this present study since an aim of this study was to contrast the findings of each of the three focus groups.

One particularly important element to account for when considering precautionary action, is that there exists a fundamental asymmetry at play in situations of potentially high and irreversible impacts. In such situations it may actually be more appropriate to focus on avoiding false negatives (i.e. avoiding a failure to anticipate damage) rather than avoiding false positives (i.e. avoiding action to avoid damage that turns out to be unnecessary) (European Environmental Agency, The 2001). If suspicions of irreversible and high damage trigger a precautionary policy measure (e.g. temporary closure) and more intensive research, then at some point the research may show that this was a false positive (e.g. the corals and/or their services were not at risk) and the precautionary 
measure can be cancelled. The losses would be economic and social benefits from not having fished those grounds during the time it took to show that there was no cause for concern. If no precautionary action is taken, but more research shows, only much later, that there was indeed real cause for concern (e.g. fishing leads to destruction of CWCs), then irreversible damages will have occurred. Participants in this study seem to have responded either as if such asymmetry between economic damage to fishermen and irreversible ecological damages to an ecosystem did not exist, or that such damage was not significant, for example because damage is local and global presence of coral continues.

This is an interesting result, which to some degree differs from attitudes to, for instance, GM foods in Europe (Nelson 2001), hazardous waste in the US (Hadden 1991) or marine mining in Australia (Mason et al. 2010) where risk or uncertainty leads to precautionary attitudes. However, it must be noted that in addition to different methods being applied in the above studies, in our analysis the respondents are confronted with a trade-off that is not just related to an 'anonymous' beneficiary of an economic activity, but to fisheries. Fishers in Norway are often associated with marginalised coastal communities that have strong social and political support. However, when asked in the questionnaire whether a fund to protect CWC should be used to compensate lost income to fishers, the majority disagreed or were neutral. There was somewhat more support for this kind of compensation if the fishers could document sustainable practices.

\section{Group discussion vs. questionnaire}

The potential role of CWC as providers of services that have use values was emphasised in the information given and the discussions that followed. Despite this, however, the questionnaire reflected that bequest values and the intrinsic right to exist (non-use values) were seen as the most important reasons to protect CWC. The latter was also found in the CWC survey by Glenn et al. (2010), and other studies on factors determining people's preferences and environmental concern (Freeman 2003, Barkmann et al. 2008). This may suggest that focus groups are less likely to reflect on some non-use and ethical concerns than stated preference methods. The range of topics that participants feel comfortable discussing may also matter. Some topics may have been more difficult to discuss among some categories of participants than others. It could be that focus group participants are reluctant to deal with sensitive topics in a discussion setting compared with a survey (Morgan, 1996). However, while respondents may not feel comfortable arguing for protection based on non-use values, it is also possible that they did not think of this argument and it was not probed further.

The different emphasis in the questionnaire responses compared to the group discussions may be due to participants being presented with clear categories which could be nonexclusively evaluated in the questionnaire. However, it is possible that the wording of the questions, including terms such as "future generations" and "intrinsic rights" could trigger respondents to lean in a particular direction. This is partly because these wordings inevitably bring new information: it is impossible to ask fully neutral questions about "intrinsic rights" because the very act of posing the question makes respondents think about these rights, whereas this may not arise so readily, or with such clarity, in a general discussion.

As found in other studies (see e.g. Álvarez-Farizo and Hanley (2006), Dietz et al. (2009)) group discussion settings may encourage social behaviours and thought 
processes in a way that the questionnaires do not. Questionnaires - especially written rather than face to face - encourage inner reflection, while the discussion encourages consideration of how others will respond to ones' arguments, and concern with 'image'. Participants may experience pressure to conform to norms of group behaviour (Maier 1967), which may, among other things, lead to strategic behaviour. There could be paradoxical results: for example, concern with what others view as realistic and solid bases for arguments may lead people to focus their statements more on tangible, shortterm values rather than on values reflecting their "true" preferences. Dietz et al. (2009) found that people were less likely to consider future generations and environmental benefits of mitigating $\mathrm{CO}_{2}$ emissions in a group setting compared to individually, and more likely to consider scientific evidence behind global warming when determining willingness to pay in a group setting. Individual questionnaires resulted in a focus on personal considerations in terms of environmental values and beliefs, while in groups people acted like policy analysts evaluating side costs and benefits, feasibility and efficiency of implementation (Dietz et al. 2009).

'Minimal group identification' (i.e. division by ostensibly trivial common features) is sufficient to encourage group members not only to favour other members of the group, but to discriminate against other groups (Tajfel 1970). A focus group setting, involving a group of individuals sharing key common characteristics, is perfectly designed for encouraging such behaviours, and this could influence expressed values. Indeed there is some evidence for this from the comments given by commercial fishers, most of them not bottom trawlers, who questioned why they should be excluded from certain areas, but not the oil industry nor the tourist fishers. Further research in this area would be warranted.

\section{Limitations of the study}

This study suffers from typical limitations associated with focus group studies. At a first glance the sample size in this present study appears small. Focus groups normally involve structured discussions among 6 to 10 homogenous strangers in a formal setting, and most studies consist of 4 to 6 focus groups (Morgan, 1996). However, group segmentation by gender, socioeconomic status or geographical location was not central to the research in this present study. Segmentation and replication would have greatly multiplied the number of groups required and in our view are not necessary given the research goals. Instead far more important for the aims of this study was an assessment of the views and attitudes of the different stakeholder/citizen groups. Also the nature and complexity of the topics under discussion required a high level of participant involvement for which small groups are deemed more effective than larger groups (Morgan, 1996). For this reason three different stakeholder groups were thought to be sufficient to meet the research goals of the study.

Furthermore, in order to not bias or influence the discussions, the facilitator avoided specifying the services and values connected to CWC, and only informed about current knowledge regarding their biology. This could have biased the results comparing discussions with the questionnaire results, as the latter specified both use- and non-use values, as well as intrinsic right to exist, while the presentation only mentioned ecological facts that can be translated into use-values. Despite these potential biases, we believe some important insight has been gained from this study concerning different stakeholder and citizen perspectives on the precautionary management of CWC. 


\section{Conclusion}

This study uses focus groups coupled with questionnaires to contrast the known current benefits of fishing versus unknown future benefits associated with $\mathrm{CWC}$. The work also investigates ideas embodied in the precautionary principle by comparing support by respondents for closure of areas confirmed to have CWC versus closures with a view to gaining information about the presence of CWC.

In general the results show that respondents believe CWC are valuable and should be protected. The study also reveals that different values are expressed spontaneously in focus groups compared with the answers given in the questionnaires. In the questionnaires, emphasis was given to non-use values such as existence and bequest value, despite the fact that use-values, particularly as habitat for fish, dominated the focus group discussions. Thus, to secure legitimacy in forming environmental policies involving such complex environmental public goods, the two approaches of gaining insights should be combined. Furthermore, deliberation to capture attitudes regarding such goods could benefit from probing specifically into the issue of non-use values.

The groups expressed reservations in both the discussions and the questionnaires towards temporary closures as a means of protecting quasi option values due to the economic consequences to fisheries. Thus the respondents reject the precautionary principle in so far as they do not condone using temporary closures as a means of gaining information about possible future benefits linked to CWC. Two reasons were given: first, some participants believed quasi-option values in the future to be small because they held the view that most CWC have already been destroyed. Secondly, many participants have positive associations with fishing communities.

Whatever the reasoning, a message here is that using temporary closures as a means of implementing the precautionary principle may receive little support. This leaves policy makers with a dilemma since the precautionary principle functions as a mechanism which allows the gathering of information needed to justify the policy in the first place, in particular in situations of irreversibility and/or high stakes. However, this study also showed that informing the public about the issues at stake, including a broad discussion regarding the plurality of values the ecosystem represents, is important when evaluating the implementation of precautionary measures.

\section{Additional files}

Additional file 1: Cold water coral focus group questionnaire.

Additional file 2: Protocol for focus groups.

Competing interests

The authors declare that they have no competing interests.

Authors' contributions

TR, JFA, CA and NF designed the focus group study. JFA and CA carried out the focus groups. JFA, NF, CA, SH, TR and RT contributed to analysis and writing the manuscript. 


\section{Author details}

${ }^{1}$ Marine Resource Economics group, Norwegian College of Fishery Science, UiT The Arctic University of Norway, 9037 Tromsø, Norway. ${ }^{2}$ Socio-Economic Marine Research Unit (SEMRU), JE Cairnes School of Business and Economics, National University of Ireland Galway, University Road, Galway, Ireland. ${ }^{3}$ Median SCP and Institut de Ciència i Tecnologia Ambientals (ICTA), Universtitat Autònoma de Barcelona, Carrer Vista Alegre 20, 08197 Valldoreix, Spain. ${ }^{4}$ J.E. Cairnes School of Business and Economics, National University of Ireland Galway, University Road, Galway, Ireland.

${ }^{5}$ Median SCP, Calle Vista Alegre, 2008197 Valldoreix, Spain.

Received: 28 April 2014 Accepted: 16 March 2015

Published online: 17 June 2015

\section{References}

Aanesen, Margrethe, Claire W Armstrong, and Luc van Hoof. 2012. The changing environment of fisheries policy in Europe. Marine Policy 36(5): 1172-1177. doi:http://dx.doi.org/10.1016/j.marpol.2012.02.002.

Abson, DJ, and M Termansen. 2011. Valuing Ecosystem Services in Terms of Ecological Risks and Returns. Conservation Biology 25(2): 250-258. doi:10.1111/j.1523-1739.2010.01623.x.

Álvarez-Farizo, Begoña, and Nick Hanley. 2006. Improving the Process of Valuing Non-Market Benefits: Combining Citizens' Juries with Choice Modelling. Land Economics 82(3): 465-478. doi:10.2307/27647723.

Anonymous. 2004. Chapter XIII. Protection of coral reefs (in Norwegian). Forskrift om utøvelse av fisket i sjøen. In FOR-200412-22-1878, ed. Industry and Fisheries Department of Trade. Norway: Industry and Fisheries Department of Trade.

Arico, S, and C Salpin. 2005. Bioprospecting of genetic resources in the deep seabed: scientific, legal and policy aspects. United Nations University - Institute of Advanced Studies (UNU-IAS) Report.

Armstrong, CW, and S van den Hove. 2008. The formation of policy for protection of cold-water coral off the coast of Norway. Marine Policy 32: 66-73.

Armstrong, C, N. Foley, R. Tinch, and S. Van den Hove. 2010. Ecosystem Goods and Services of the Deep. HERMIONE FP7.

Armstrong, Claire W, Naomi Foley, Rob Tinch, and Sybille van den Hove. 2012. Services from the Deep: Steps towards valuationof deep sea goods and services. Ecosystems Services 2: 2-13.

Barkmann, J, K Glenk, A Keil, C Leemhuis, N Dietrich, G Gerold, and R Marggraf. 2008. Confronting unfamiliarity with ecosystem functions: The case for an ecosystem service approach to environmental valuation with stated preference methods. Ecological Economics 65(1): 48-62. doi:10.1016/j.ecolecon.2007.12.002.

CICES. 2013. Common International Classification of Ecosystem Services. Accessed 8 Aug http://cices.eu.

Crabtree, BF, MK Yanoshik, WL Miller, and PJ O'Connor. 1993. Selecting individual or group interviews. In Successful focus groups: Advancing the state of the art, ed. DL Morgan. Thousands Oaks, CA: Sage.

Defra. 2007. An introductory guide to valuing ecosystem services. London: Department for Environment, Food and Rural Affairs.

Dietz, T, PC Stern, and A Dan. 2009. How deliberation affects stated willingness to pay for mitigation of carbon dioxide emissions: an experiment. Land Economics 85(2): 329-347.

Duncan, Marie T, and David L Morgan. 1994. Sharing the caring: family caregivers' views of their relationships with nursing home staff. The Gerontologist 34(2): 235-244.

European Environmental Agency, The. 2001. Late lessons from early warnings: the precautionary principle 1896-2000. In Environmental issue report No 22, ed. P Harremoës, D Gee, MG Malcolm, Stirling Andrew, J Keys, B Wynne, and $S$ Guedes Vaz. Luxembourg: Office for Official Publications of the European Communities.

Foley, Naomi S, Tom M van Rensburg, and Claire W Armstrong. 2010. he ecological and economic value of cold-water coral ecosystems. Ocean \& Coastal Management 53(7): 313-326. doi:10.1016/j.ocecoaman.2010.04.009.

Fosså, JH, PB Mortensen, and DM Furevik. 2002. The deep water coral Lophelia pertusa in Norwegian waters: distribution and fishery impacts. Hydrobiologia 471: 1-12.

AM Freeman, AMyrick. 2003. The measurement of environmental and resource values: theory and methods. Washington, D.C.: Resources for the Future.

Freiwald, A, JH Fosså, A Grehan, T Koslow, and JM Roberts. 2004. Cold water coral reefs: out of sight - no longer out of mind. Camebridge, UK: UNEP-WCMC.

Garcia, SM, A Zerbi, C Aliaume, T Do Chi, and G Lasserre. 2003. The ecosystem approach to fisheries. Issues, terminology, principles, institutional foundaitons, implementation and outlook. In FAO Fisheries Technical Paper. Rome: FAO.

Gezelius, SS, and K Refsgaard. 2007. Barriers to rational decision-making in environmental planning. Land Use Policy 24(2): 338-348. doi:10.1016/j.landusepol.2006.04.002.

Glenn, H, P Wattage, S Mardle, T Van Rensburg, A Grehan, and N Foley. 2010. Marine protected areas-substantiating their worth. Marine Policy 34(3): 421-430

Hadden, Susan G. 1991. Public Perception of Hazardous Waste. Risk Analysis 11(1): 47-57. doi:10.1111/j.15396924.1991.tb00568.x

Howarth, RB, and MA Wilson. 2006. A theoretical approach to deliberative valuation: aggregation by mutual consent. Land Economics 82: 1-16.

Husebø, AL Nøttestad, JH Fosså, DM Furevik, SB Jørgensen. 2002. Distribution and abundance of fish in deep-sea coral habitats. Hydrobiologia 471:91-99.

Jackson, JBC, MX Kirby, WH Berger, KA Bjorndal, LW Botsford, BJ Bourque, RH Bradbury, R Cooke, J Erlandson, JA Estes, TP Hughes, S Kidwell, CB Lange, HS Lenihan, JM Pandolfi, CH Peterson, RS Steneck, MJ Tegner, and RR Warner. 2001. Historical overfishing and the recent collapse of coastal ecosystems. Science 293: 629-638.

Kahane, David, Kristjana Loptson, Jade Herriman, Max Hardy. 2013. Stakeholder and Citizen Roles in Public Deliberation. Journal of Public Deliberation 9 (2):Article 2.

Kumar, M, and P Kumar. 2008. Valuation of the ecosystem services: A psycho-cultural perspective. Ecological Economics 64(4): 808-819. doi:10.1016/j.ecolecon.2007.05.008. 
LaRiviere, Jacob, Mikołaj Czajkowski, Nick Hanley, Margrethe Aanesen, Jannike Falk-Petersen, and Dugald Tinch. 2014. The Value of Familiarity: Effects of Knowledge and Objective Signals on Willingness to Pay for a Public Good. Journal of Environmental Economics and Management 68: 376-389.

Liu, S., R Costanza, S Farber, A. Troy. 2010. Valuing ecosystem services Theory, practice, and the need for a transdisciplinary synthesis. Annals of the New York Academy of Sciences, In Ecological Economics Reviews, 1185: 54-78.

Lo, Alex Y, and Clive L Spash. 2013. Deliberative monetary valuation: In search of a democratic and value plural approach to environmental policy. Journal of Economic Surveys 27(4): 768-789. doi:10.1111/j.1467-6419.2011.00718.x.

Lutringer, A, D Blamart, N Frank, and L Laberyrie. 2005. Paleotemperatures from deep-sea corals: scale effects. In Cold-water corals and ecosystems, ed. A Freiwald and J Roberts, 1097-1108. Berlin Heidelberg: Springer-Verlag.

Maclsaac, K, C Bourbannais, E Kenchington, D Gordon, and S Gass. 2001. Observations on the occurrence and habitat preference of corals in Atlantic Canada. In First International Symposium on Deep-Sea Corals, ed. JHM Willison, $J$ Hall, SE Gass, ELR Kenchington, M Butler, and P Doherty, 58-75. Halifax, Nova Scotia: Ecology Action Centre.

Maier, Norman R. 1967. Assets and liabilities in group problem solving: the need for an integrative function. Psychological Review 74(4): 239-249. doi:10.1037/h0024737.

Mason, Claire, Paxton Gillian, Parr Joanna, and Boughen Naomi. 2010. Charting the territory: Exploring stakeholder reactions to the prospect of seafloor exploration and mining in Australia. Marine Policy 34(6): 1374-1380. doi:http://dx.doi.org/10.1016/j.marpol.2010.06.012.

MEA. 2005. Ecosystems and Human Well-being: Synthesis. Washington, DC: Millennium Ecosystem Assessment, Island Press.

Morgan, David L. 1996. Focus Groups. Annual Review of Sociology 22: 129-152. doi:10.2307/2083427.

Morris, J, A Wildavsky, W Beckerman, T Gilland, HI Miller, G Conko, CT Rubin, H Guldberg, B Durodie, B Yandle, IM Goklany, and R Matthews. 2000. Rethinking risk and the precautionary principle. Edited by J. Morris. Oxford: Butterworth-Heinemann

Munda, Giuseppe. 2004. Social multi-criteria evaluation: Methodological foundations and operational consequences. European Journal of Operational Research 158(3): 662-677. doi:http://dx.doi.org/10.1016/50377-2217(03)00369-2.

Myers, RA, and B Worm. 2003. Rapid worldwide depletion of predatory fish communities. Nature 423(6937): 280-283.

Nelson, Carl H. 2001. Risk Perception, Behavior, and Consumer Response to Genetically Modified Organisms: Toward Understanding American and European Public Reaction. American Behavioral Scientist 44(8): 1371-1388. doi:10.1177/00027640121956737.

Niemeyer, S, and CL Spash. 2001. Environmental valuation analysis, public deliberation, and their pragmatic syntheses: a critical appraisal. Environment and Planning C 19(4): 567-585. doi:citeulike-article-id:2749103.

Pearce, D, and D Moran. 1994. The economic value of biodiversity. London: Earthscan Publications Limited.

Perman, R, Y Ma, M Common, D Maddison, and J McGilvray. 2011. Natural Resource and Environmental Economics. London: Pearson Education Limited.

Puglise, KA, RJ Brock, and JJ MCDonough. 2005. Identifying critical information needs and developing institutional partnerships to further the understanding of Atlantic deep-sea coral ecosystems. In Cold-water corals and ecosystems, ed. A Freiwald and JM Roberts, 1129-1140. Berlin-Heidelberg: Springer-Verlag.

Sagoff, M. 1998. Aggregation and deliberation in valuing environmental public goods: A look beyond contingent pricing. Ecological Economics 24(2-3): 213-230. doi:10.1016/s0921-8009(97)00144-4.

Söderholm, Patrik. 2001. The Deliberative Approach in Environmental Valuation. Journal of Economic Issues 35(2): 487-495. doi:10.2307/4227681

Soma, Katrine, and Arild Vatn. 2010. Is there anything like a citizen? A descriptive analysis of instituting a citizen's role to represent social values at the municipal level. Environmental Policy and Governance 20(1): 30-43. doi:10.1002/ eet.529.

Spash, CL. 2006. Non-economic motivation for contingent values: Rights and attitudinal beliefs in the willingness to pay for environmental improvements. Land Economics 82(4): 602-622.

Tajfel, H. 1970. Experiments in intergroup discrimination. Scientific American 223: 96-102.

TEEB. 2010. The Economics of Ecosystems and Biodiversity: Mainstreaming the Economics of Nature: A synthesis of the approach, conclusions and recommendations of TEEB.

Tinch, Rob, Claire W, Armstrong, S, van den Hove. 2011. Report on policy demands for value evidence. In Deliverable 6.3 of HERMIONE (Hotspot Ecosystem Research and Man's Impact on European Seas) project. http://medianweb.eu/MG/pdf/hermione-policy demands.pdf.

Turner, RK Morse-Jones, S, and Fisher B. 2010. Ecosystem valuation. Annals of the New York Academy of Sciences 1185(1): 79-101. doi:10.1111/j.1749-6632.2009.05280.x.

UNESCO. 2005. The Precautionary Principle. World: Commission on the Ethics of Scientific Knowledge and Technology.

van den Hove, S. 2000. Participatory approaches to environmental policy-making: the European Commission Climate Policy Process as a case study. Ecological Economics 33(3): 457-472. doi:10.1016/s0921-8009(99)00165-2.

van den Hove, Sybille. 2006. Between consensus and compromise: acknowledging the negotiation dimension in participatory approaches. Land Use Policy 23(1): 10-17. doi:http://dx.doi.org/10.1016/j.landusepol.2004.09.001.

Wattage, P, H Glenn, S Mardle, T Van Rensburg, A Grehan, and N Foley. 2011. Economic value of conserving deep-sea corals in Irish waters: A choice experiment study on marine protected areas. Fisheries Research 107(1-3): 59-67. doi:10.1016/j.fishres.2010.10.007.

Wilson, Matthew A, and Richard B Howarth. 2002. Discourse-based valuation of ecosystem services: establishing fair outcomes through group deliberation. Ecological Economics 41(3): 431-443. doi:10.1016/s0921-8009(02)00092-7. 